\begin{tabular}{|c|l|}
\hline Title & $\begin{array}{l}\text { Phylogeography of the Japanese white toothed shrew (Eulipotyphla:Soricidae): a clear division of haplogroups between } \\
\text { eastern and western Japan and their recent introduction to some regions }\end{array}$ \\
\hline Author(s) & $\begin{array}{l}\text { Ohdachi, Satoshi D.; Y oshizawa, Kazunori; Takada, Y asushi; Motokawa, Masaharu; Iwasa, Masahiro A.; A rai, Satoru; } \\
\text { Moribe, Junji; U ematsu, Y asushi; Sakai, Eiichi; Tateishi, Takashi; Oh, Hong-Shik; Kinoshita, Gohta }\end{array}$ \\
\hline Citation & $\begin{array}{l}\text { Mammal Study, 43(4), 245-259 } \\
\text { https://doi.org/40.3106/ms2017-0059 }\end{array}$ \\
\hline Issue Date & 201810-19 \\
\hline Doc URL & http:/hdl.handle.net/2115/76242 \\
\hline Type & article \\
\hline File Information & Mammal Study 43(4)_245-259.pdf \\
\hline
\end{tabular}

Instructions for use 


\section{BioOne COMPLETE}

\section{Phylogeography of the Japanese White-Toothed Shrew (Eulipotyphla: Soricidae): A Clear Division of Haplogroups between Eastern and Western Japan and their Recent Introduction to Some Regions}

Authors: Satoshi D. Ohdachi, Kazunori Yoshizawa, Yasushi Takada, Masaharu Motokawa, Masahiro A. Iwasa, et. al.

Source: Mammal Study, 43(4) : 245-259

Published By: Mammal Society of Japan

URL: https://doi.org/10.3106/ms2017-0059

BioOne Complete (complete.BioOne.org) is a full-text database of 200 subscribed and open-access titles in the biological, ecological, and environmental sciences published by nonprofit societies, associations, museums, institutions, and presses.

Your use of this PDF, the BioOne Complete website, and all posted and associated content indicates your acceptance of BioOne's Terms of Use, available at www.bioone.org/terms-of-use.

Usage of BioOne Complete content is strictly limited to personal, educational, and non-commercial use. Commercial inquiries or rights and permissions requests should be directed to the individual publisher as copyright holder.

BioOne sees sustainable scholarly publishing as an inherently collaborative enterprise connecting authors, nonprofit publishers, academic institutions, research libraries, and research funders in the common goal of maximizing access to critical research. 


\title{
Phylogeography of the Japanese white-toothed shrew (Eulipotyphla: Soricidae): a clear division of haplogroups between eastern and western Japan and their recent introduction to some regions
}

\author{
Satoshi D. Ohdachi ${ }^{1, *}$, Kazunori Yoshizawa ${ }^{2}$, Yasushi Takada ${ }^{3}$, Masaharu Motokawa ${ }^{4}$, \\ Masahiro A. Iwasa ${ }^{5}$, Satoru Arai ${ }^{6}$, Junji Moribe ${ }^{7}$, Yasushi Uematsu ${ }^{8}$, Eiichi Sakai ${ }^{9}$, \\ Takashi Tateishi' ${ }^{10}$, Hong-Shik $\mathrm{Oh}^{11}$ and Gohta Kinoshita ${ }^{12}$ \\ ${ }^{1}$ Institute of Low Temperature Science, Hokkaido University, Kita 19 Nishi 8, Kita-ku, Sapporo 060-0819, Japan \\ 2 Systematic Entomology, Graduate School of Agriculture, Hokkaido University, Kita-ku, Sapporo 060-8589, Japan \\ ${ }^{3}$ Jojo 3-76-2, Kasugai, Aichi 486-0833, Japan \\ ${ }^{4}$ The Kyoto University Museum, Kyoto University, Yoshida Honmachi, Sakyo-ku, Kyoto 606-8501, Japan \\ ${ }^{5}$ College of Bioresource Sciences, Nihon University, Kameino 1866, Fujisawa, Kanagawa 252-0880, Japan \\ ${ }^{6}$ Infectious Disease Surveillance Center, National Institute of Infectious Diseases, Toyama 1-23-1, Shinju-ku, Tokyo 162-8640, \\ Japan \\ ${ }^{7}$ Research Center for Wildlife Management, Gifu University, Yanagido 1-1, Gifu 501-1193, Japan \\ ${ }^{8}$ Department of Anatomy, School of Dentistry, Aichi-Gakuin University, Kusumoto-cho, Chikusa-ku, Nagoya 464-8650, Japan \\ ${ }^{9}$ Department of Dental Hygiene, Aichi-Gakuin Junior College, Kusumoto-cho, Chikusa-ku, Nagoya 464-8650, Japan \\ ${ }^{10}$ Jonan, Fujisawa, Kanagawa 251-0057, Japan \\ ${ }^{11}$ Faculty of Science Education, Jeju National University, Ara-dong 1, Jeju, Jeju-do 690-756, Republic of Korea \\ ${ }^{12}$ Laboratory of Forest Biology, Division of Forest \& Biomaterials Science, Graduate School of Agriculture, Kyoto University, \\ Sakyo-ku, Kyoto 606-8502, Japan
}

\begin{abstract}
The Japanese white-toothed shrew (Crocidura dsinezumi) is a species endemic to Japan. For this species, only minimal phylogeographic investigations have been conducted. We obtained DNA sequences of mitochondrial cytochrome $b$ and control region and nuclear $A p o B$ genes for 191 individuals of $C$. dsinezumi from 107 locations collected throughout its known range. In the phylogenetic trees based on mitochondrial DNA sequences, two haplogroups (Eastern and Western Clades) were recognized, and the demarcation line between them was located in central Honshu without an overlapping area. The estimated divergence time between the two major clades indicated that they could have diverged prior to the final geologic division of Hondo and the Asian Continent (100-150 KYA). For the $A p o B$ gene, Types A, G, and R (heterozygote) were recognized although there was a single site mutation. Type A mainly occurs in eastern and central Japan and Types $\mathrm{G}$ and $\mathrm{R}$ in central and western Japan. It was suggested in the present study that some shrews in Hokkaido were introduced recently from eastern Honshu (possibly the Tohoku Region) whereas others might have been distributed there naturally, and that population in Jeju (South Korea) was introduced recently from Kyushu.
\end{abstract}

Key words: $A p o B$, biogeography, cytb, Hokkaido, Jeju.

The Japanese white-toothed shrew, Crocidura dsinezumi (Temminck, 1842) (Soricidae, Eulipotyphla), is a species endemic to Japan and is found in most regions there excepting the Ryukyu Islands (Motokawa 2015a). In addition, $C$. dsinezumi occurs remotely on Jeju (Cheju) Island, South Korea (Motokawa 2015a). The species most closely related to C. dsinezumi are C. lasiura and C. rapax (previously classified as C. kurodai) in the Asian Continent and Taiwan (Motokawa et al. 2000; Ohdachi et al. 2006). Fossils referred as $C$. dsinezumi are recorded from the Middle and Late Pleistocene in Honshu and Kyushu (Tomida and Sakura 1991). Thus, C. dsinezumi has been widely distributed in the Japanese Archipelago (excepting the Ryukyus) at least since the Middle Pleistocene

*To whom correspondence should be addressed.E-mail: ohd@lowtem.hokudai.ac.jp 
but occurs neither in the Asian Continent nor Taiwan. Therefore, $C$. dsinezumi is one of key species to investigate the establishment of the Japanese mammalian fauna. There have been some previous investigations about phylogeography of $C$. dsinezumi (Han et al. 2002; Ohdachi et al. 2004; Ohdachi 2008) to reveal the biogeographic history of this species but these studies are not enough for full understanding because of limited numbers of sampling locations. In addition, time scale of diversification among the phylogroups has not been investigated in $C$. dsinezumi.

It was known that there were two major haplogroups of the mitochondrial cytochrome $b$ gene, which occurs in eastern and western Japan, respectively, in $C$. dsinezumi (Ohdachi et al. 2004; Ohdachi 2008). Furthermore, previous phylogenetic studies (Han et al. 2002; Ohdachi et al. 2004) suggested that the populations in Hokkaido and Jeju Island might have been introduced by humans from somewhere in the Hondo Region (Honshu, Shikoku, and Kyushu). However, the exact distribution of the haplogroups and the detailed origins of the Hokkaido and Jeju populations are still unknown, because the sampling locations of these previous studies were limited.

In addition, there are two morphological studies based on cranial or mandibular traits in C. dsinezumi (Motokawa 2003; Takada et al. 2013). Motokawa (2003) demonstrated that the shrew tended to decrease in cranial size from southwest to northeast in Japan, but the cranial size of populations in Hokkaido and Kuchinoerabu Island (of the Ōsumi Islands) were larger than expected. Furthermore, Motokawa (2003) suggested that populations from Kuchinoerabu Island and Nakanoshima Island (of the Tokara Islands) might constitute a new subspecies of $C$. dsinezumi, because morphologically individuals from these islands differed largely from known subspecies. Takada et al. (2013) suspected, based on mandible morphology, that the population of the Izu Islands was related to the population on the Kyushu mainland. However, the phylogenetic relationships among those local populations in those studies (Motokawa 2003; Takada et al. 2013) have not been studied.

In the present paper, the intraspecific phylogeny of $C$. dsinezumi was examined by nucleotide sequencing of the mitochondrial cytochrome $b$ gene and control region, as well as the nuclear apolipoprotein B $(A p o B)$ gene, based on intensive sampling throughout the shrew's known range. The two mitochondrial genes are conventionally used for phylogeographic studies in mammals, but they can only be used to trace the maternal lineage. In this paper, the nuclear $A p o B$ gene, which has been used in phylogeographic investigations of Crocidura species (Dubey et al. 2007), was used to complement the result of the mitochondrial genes survey.

The main purpose of the present paper is to reveal the biogeographic history of $C$. dsinezumi, and there are three sub-purposes. First, it is to clarify the precise demarcation between the ranges of the two major haplogroups (the eastern and western groups) indicated in previous studies (Han et al. 2002; Ohdachi et al. 2004) and the origins of the populations in Hokkaido and Jeju Island. Secondly, the genetic relationships among local populations mentioned in previous morphological studies (Motokawa 2003; Takada et al. 2013) are investigated throughout the range of $C$. dsinezumi. Finally, we estimate the divergence time of some haplogroups, applying the molecular clock method based on $c y t b$ gene sequences.

\section{Materials and methods}

\section{Sampling}

Tissues of the total 193 shrews (including outgroup species) in the present study were obtained from samples captured by the present authors using small plastic pitfall traps and Sherman traps (Ohdachi 1995; Takada et al. 2013) and special traps designed by Hattori et al. (1986), and those provided by some museums and researchers (see Acknowledgments). The shrews captured by the present authors are preserved in the Natural History Museum of Botanical Garden, Hokkaido University (Sapporo, Japan), the University Museum, the University of Tokyo (Tokyo, Japan), the Kyoto University Museum (Kyoto, Japan), and Jeju National University (Jeju City, the Republic of Korea). The 191 individuals of $C$. dsinezumi were from 107 locations (Fig. 1). Crocidura rapax from Taiwan and C. lasiura from South Korea (Ohdachi et al. 2004) were used as outgroup species (one individual each, respectively), since these two species are sister species to C. dsinezumi (Ohdachi et al. 2004, 2006; Lin and Motokawa 2014). See Supplementary Table S1 for abbreviations and the collection locations for each shrew sample.

\section{DNA Sequencing}

Nucleotides of the mitochondrial cytochrome $b$ gene $(c y t b)$ and the control region (D-loop) were sequenced following Ohdachi et al. (2012) and Arai et al. (2012). In addition to the primers of the previous papers, new primers were also designed for $c y t b$ gene and used when 


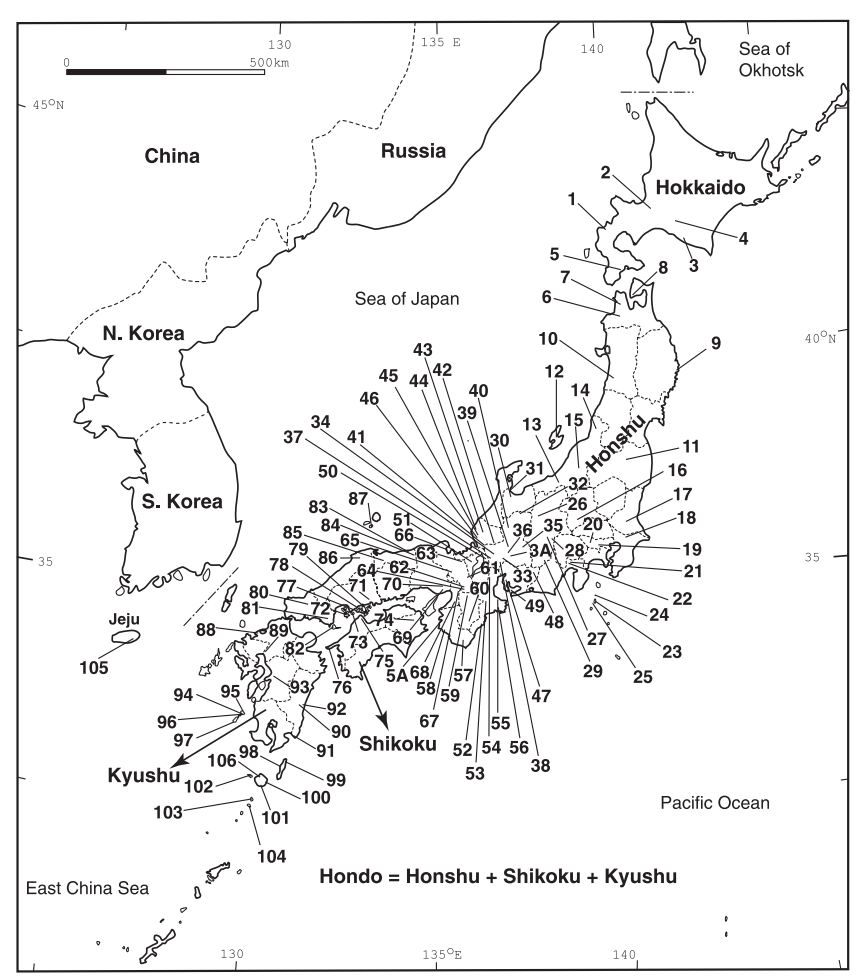

Fig. 1. Collection locations for Crocidura dsinezumi in the present study. Detailed location names are given in Supplementary Table S1.

needed. These are DsiCytb620f: 5'-TACATGAAACCGG CTCAAACAA-3' (L15370) as a forward primer as well as DsiCytb650r: 5'-ATAATAAGGGTGGAAGGGAATT3' (H15401), and DsiCytb1155r: 5'-TTACAAGACCAG TGTATTGATTGTA-3' (H15927) as reverse primers. Here, the position numbers are those corresponding to the $3^{\prime}$ end of $\mathrm{L}$ and $\mathrm{H}$ strands of the human mitochondrial genome (Anderson et al. 1981). The nuclear apolipoprotein B $(A p o B)$ gene was sequenced only for individuals arbitrarily chosen among the samples, using the primer pair ApoBf and ApoBr of Dubey et al. (2007). PCR conditions of those genes (annealing temperature, cycle, PCR kit, etc.) were the same as in the previous studies (Ohdachi et al. 2006; Dubey et al. 2007; Arai et al. 2012; Ohdachi et al. 2012). In addition, some sequences were obtained from the DNA database (DDBJ/GenBank/ EMBL). See Supplementary Table S1 for sources of the nucleotide sequences and samples used in the present study.

\section{Phylogenetic analysis}

Phylogenetic analysis was conducted using the sequence data obtained in the present study and from the DNA database. Because sequences of the nuclear $A p o B$ gene showed only one variable site, this gene was not used in the reconstruction of the phylogenetic tree.

Two data sets were analysed: $c y t b$ and the combined data of $c y t b+$ the control region. For the combined data set, only individuals which had both $c y t b$ and the control region sequences were included. Alignments of $c y t b$ sequences were straightforward because of the lack of insertions/deletions. The total length of cytb sequence used for analysis was $1140 \mathrm{bp}$. The control region sequences were composed of conservative regions near the $5^{\prime}$ and $3^{\prime}$ ends and a highly variable tandem repeat region in the middle part (Ohdachi et al. 2012). The number of repeats was highly variable among individuals, and homology of each unit of repeats could not be warranted with confidence. Therefore, the tandem repeat region (excepting the first and last terminal motifs of the repeated region) was omitted in the analysis. Sequences of the control region were initially aligned using MAFFT ver. $6.857 \mathrm{~b}$ (Katoh et al. 2005) and edited by eye according to the similarity criterion (Simmons 2004). The regions with indels were also excluded from the analyses. As a result, the total length used in the analysis of the control region was $608 \mathrm{bp}$.

We applied maximum likelihood (ML) and Bayesian (BI) analyses to estimate the phylogenetic relationships. For ML analysis, all data were combined into a single matrix and the ML tree was searched using PhyML 3.1 (Guindon et al. 2010) with the best fit model (HKY model: all parameters estimated from the data set) selected by the hierarchical likelihood ratio test as implemented in Modeltest ver. 3.7 (Posada and Crandall 1998). A heuristic search with SPR (subtree pruning regrafting) branch swapping was performed with a neighbor joining (NJ) tree as a starting tree. Bootstrap support values were calculated with 1000 replications of SPR branch swapping using PhyML 3.1 (Guindon et al. 2010). For BI analysis, we used MrBayes ver. 3.2.6 (Ronquist et al. 2012). Data were subdivided into the following four categories (first, second, and third codon positions of $c y t b$, and the control region). The best fit model for BI search was selected using the hierarchical likelihood ratio test as implemented in MrModeltest ver. 2.3 (Nylander 2004). A different substitution model was applied for each category: K2P for 1st position of $c y t b, \mathrm{HKY}$ for 2nd position of $c y t b, \mathrm{GTR}+\mathrm{G}$ for 3rd position of $c y t b$, and HKY $+\mathrm{G}+\mathrm{I}$ for the control region. See the NEXUS file (Supplementary Data S1) for details. We performed two runs each with four chains for 10000000 generations and trees were sampled every 1000 generations. First $10 \%$ of 
trees were excluded for burn-in. Then, a 50\% majority rule consensus tree was computed using the rest of trees to obtain Bayesian posterior probabilities. Crocidura lasiura and C. rapax were used as outgroup species. We applied the tree reconstruction procedure above for the combined data sets of $c y t b+$ the control region (1748 bp). Additionally, BI analysis using cytb only (1140 bp) was conducted with the same calculation procedure as in the combined data set. In the present paper, only ML trees were shown although both of the bootstrap values for ML method and the posterior probabilities for BI method were indicated in the ML trees. The sequence data matrix and the calculation condition used in the present analyses are given in the NEXUS file (Supplementary Data S1).

\section{Mismatch test, neutrality test, and genetic differentiation}

Mismatch test, neutrality tests using Fu's $F_{S}$ and Tajima's $D$, and pairwise genetic differentiation test using $\Phi_{S T}$ were analysed using ARLEQUIN ver. 3.5.2.2 (Excoffier and Lischer 2010), based on the data set of $c y t b$. Mismatch test and neutrality test were performed to detect rapid population expansion for each local population. In the mismatch test, the expected distribution was simulated under the sudden expansion model. The validity of the sudden expansion model was tested with a parametric bootstrap approach with 1000 replications under the assumption of pure demographic expansion, based on the sum of squared deviations (SSD) (Schneider and Excoffier 1999). The raggedness index was also calculated to test population expansion. The neutrality test was performed, testing the significance of each statistics from 1000 simulated samples. Genetic differentiation among five local populations was estimated by pairwise $\Phi_{S T}$, evaluating the significance using 100 permutations. The five populations are those from (1) eastern Honshu (eastern Japan excluding Hokkaido), (2) Hokkaido, (3) western Hondo (western Japan excluding the Ōsumi \& Tokara Islands and Jeju), (4) the Ōsumi \& Tokara Islands (Tane, Yaku, Kuchinoerabu, and Nakanoshima islands), and (5) Jeju Island. Note that the grouping was based on geographical location, not corresponding to clades of phylogenetic trees, but the border line between eastern Honshu and western Hondo populations was the same as that between Eastern and Western Clades of phylogenetic trees (see Results section).

\section{Estimation of divergence time}

Divergence times were estimated for eight nodes of the cytb phylogenetic tree (Fig. 3). Because paleobiologi- cal investigations of $C$. dsinezumi were scarce and the fossil records could not be used for calibration points, we estimated divergence time using different rates of the molecular clock. Dating analysis was performed by constructing a Bayesian phylogenetic tree using BEAST version 2.3.0 (Bouckaert et al. 2014) based on the data set of $c y t b$. The data set was analyzed with HKY model of nucleotide substitution, using a constant coalescent population size as the tree prior. The clock rate of $2-4 \%$ (substitution/site/million years) on mitochondrial genes was proposed more than three decades ago (Brown et al. 1979; Brown 1980; Miyata et al. 1982), and traditionally has been applied in estimating evolutionary timescales for mammals. However, the evolutionary rate is now considered to vary among lineages and time scales (Ho et al. 2005; Nabholz et al. 2008). Hence, we applied both slow and fast evolutionary rates to estimate divergence time. For slow evolutionary assumption, three rates $(2 \%$, $3.1 \%$, and $4 \%$ ) were used, based on conventional criteria (Brown et al. 1979; Brown 1980; Miyata et al. 1982). For the fast evolutionary assumption, three rates $(8 \%$, $12 \%$, and $17.1 \%$ ) were used. These three fast rates were estimated for the large Japanese field mouse (Apodemus speciosus), postulating range-expansion time of 15 kiloyears ago (KYA), 10 KYA, and 7 KYA based on geologic events around the Japanese Archipelago after the last glacial maximum ( 20 KYA; Suzuki et al. 2015). We performed independent runs for these six clock rates $(2 \%, 3.1 \%, 4 \%, 8 \%, 12 \%$, and $17.1 \%)$ under a strict clock model. Bayesian searches for each analysis were conducted using the Markov Chain Monte Carlo (MCMC) method for 50000000 generations, and chains were sampled every 5000 generations, discarding the first 5000000 generations as burn-in. Tracer v1.6 (Rambaut and Drummond 2007) was used to confirm convergence of MCMC chains and the effective sample size (ESS) values exceeding 200 for all parameters. Trees were summarized as maximum clade credibility (MCC) trees using TreeAnnotator 2.3.0 (available in the BEAST v.2.1.3 package; http://beast.bio.ed.ac.uk/treeannotator), and node ages were obtained from FigTree 1.4.0 (Rambaut 2012) with the 95\% highest posterior density (HPD) intervals.

\section{Results}

\section{Sequencing}

For the mitochondrial cytb gene, the full $1140 \mathrm{bp}$ region of 157 individuals of $C$. dsinezumi was successfully 
sequenced in the present study. For the mitochondrial control region, 375-774 bp in the former region and 233$694 \mathrm{bp}$ in the latter region in 169 individuals (including one individual each of $C$. lasiura and $C$. rapax) were sequenced. The former and latter sequences for an individual could not be ligated because the middle part of the control region could not be obtained completely. For the nuclear $A p o B$ gene, partial 537 bp region of 132 shrews (including one individual of $C$. lasiura) were sequenced (540 bp for $C$. lasiura). Two sequence data of cytb (AB066250 and $\mathrm{AB}$ 077147) were renewed (replaced with correct sequence) in the present study. See Supplementary Table S1 for details of the samples used in the present study.

\section{Phylogeny based on mitochondrial DNA}

Topologies of the phylogenetic tree based on the combined data set of the $c y t b$ and the mitochondrial control region (Fig. 2) and the cytb data set only (Fig. 3) were fundamentally the same, although the number of OTUs in the combined data set was smaller than that of $c y t b$ only (Supplementary Table S1). To avoid redundancy, the result of the phylogenetic tree of the combined data set (Fig. 2) was described primarily below.

In the phylogenetic tree based on the combined data set of the cytb and the control region, there were two unambiguous phylogroups (Eastern and Western Clades) (Fig. 2). Within the Eastern Clade, there were no clear subclades except for some shrews from the same localities. Within the Western Clade, two subclades were recognized: Western Hondo-Jeju Clade and Ōsumi-Tokara Islands Clade (Fig. 2). Western Hondo-Jeju Clade consists of shrews from western Honshu, Shikoku, Kyushu, and Jeju (South Korea), and Ōsumi-Tokara Islands Clade consists of those from Yaku and Kuchinoerabu islands (the Ōsumi Islands without Tane Island) and the Tokara Islands (See Figs. 4 and 5 for locations). Shrews from Tane Island were not clustered in Ōsumi-Tokara Islands Clade (Figs. 2 and 3) although this island is geographically included in the Ōsumi Islands. Further, within Western Hondo-Jeju Clade, there were some infrasubclades with high supporting values (Fig. 2). Shrews from Kamikoshiki Island (except one individual, KKS1) and Nakakoshiki and Shimokoshiki islands formed different subclades: Kamikoshiki Island Main Clade and Nakakoshiki-Shimokoshiki Islands Clade for each (Fig. 2; See Figs. 4 and 5 for the locations of these islands). One individual from Kamikoshiki Island (KKS1, pointed by a black triangle in Fig. 2) was phylogenetically distantly located from Kamikoshiki Island Main Clade. In this way, shrews from the Koshiki-jima Islands (consisting of Kamikoshiki, Nakakoshiki, and Shimokoshiki islands) were divided into three distinct clades.

The shrews from Hokkaido were clustered into a clade based on the combined data set (Fig. 2). However, based on the data set of $c y t b$ only (Fig. 3), four individuals from Hokkaido (Group 2) made a monophyletic group with two individuals from the Tohoku Region (IWT1 and AKT2), and the rest (Group 1) were not clustered in one group and had an identical haplotype with some shrews in eastern Honshu. The shrews from Jeju Island were clustered into a clade with those from Kyushu although the confidence value of the node was low in the ML analysis based on the combined data set (Figs. 2 and 3).

Haplogroup distribution of the Eastern and Western Clades is plotted in Fig. 4 based on the sequences of the $c y t b$ and/or the control region (Supplementary Table S1). The demarcation line between the ranges of the two major clades extends from the eastern part of Fukui Prefecture in the north to the border between Aichi and Mie Prefectures in the south via the central part of Gifu Prefecture (Fig. 4). The demarcation was clear and the ranges of the two clades did not overlap.

\section{Nuclear ApoB gene type}

In the nuclear $A p o B$ gene sequence, there was a single variable site at the 97 th position among the $537 \mathrm{bp}$ region sequenced. Three genetic types were recognized; the type which has only adenine (A) at the variable site is Type A, those that have only guanine $(\mathrm{G})$ are Type $\mathrm{G}$, and those that have both A and G are Type R. Thus, Types A and $\mathrm{G}$ are homozygotes and Type $\mathrm{R}$ is a heterozygote. In addition, C. lasiura and C. rapax, which are outgroup species, had only guanine at the corresponding site of the 97th position in C. dsinezumi and three more nucleotides (totally $540 \mathrm{bp}$ ).

Type A mainly occurred in the eastern (the Kanto and Tohoku Regions) and central (the Chubu and the Kinki Regions) parts of Japan, whereas Types G and R appeared in the central and western parts of Japan (Fig. 5). Type A also occurred in some localities in Tottori and Miyazaki Prefectures and Yaku Island in western Japan. Additionally, Hokkaido and Jeju shrews had Types A and G, respectively.

Mismatch test, neutrality test, and genetic differentiation

Mismatch test showed that there was no significant deviation between observed and simulated values for all of the groups $(P>0.05)$ based on SSD (sum of squared 


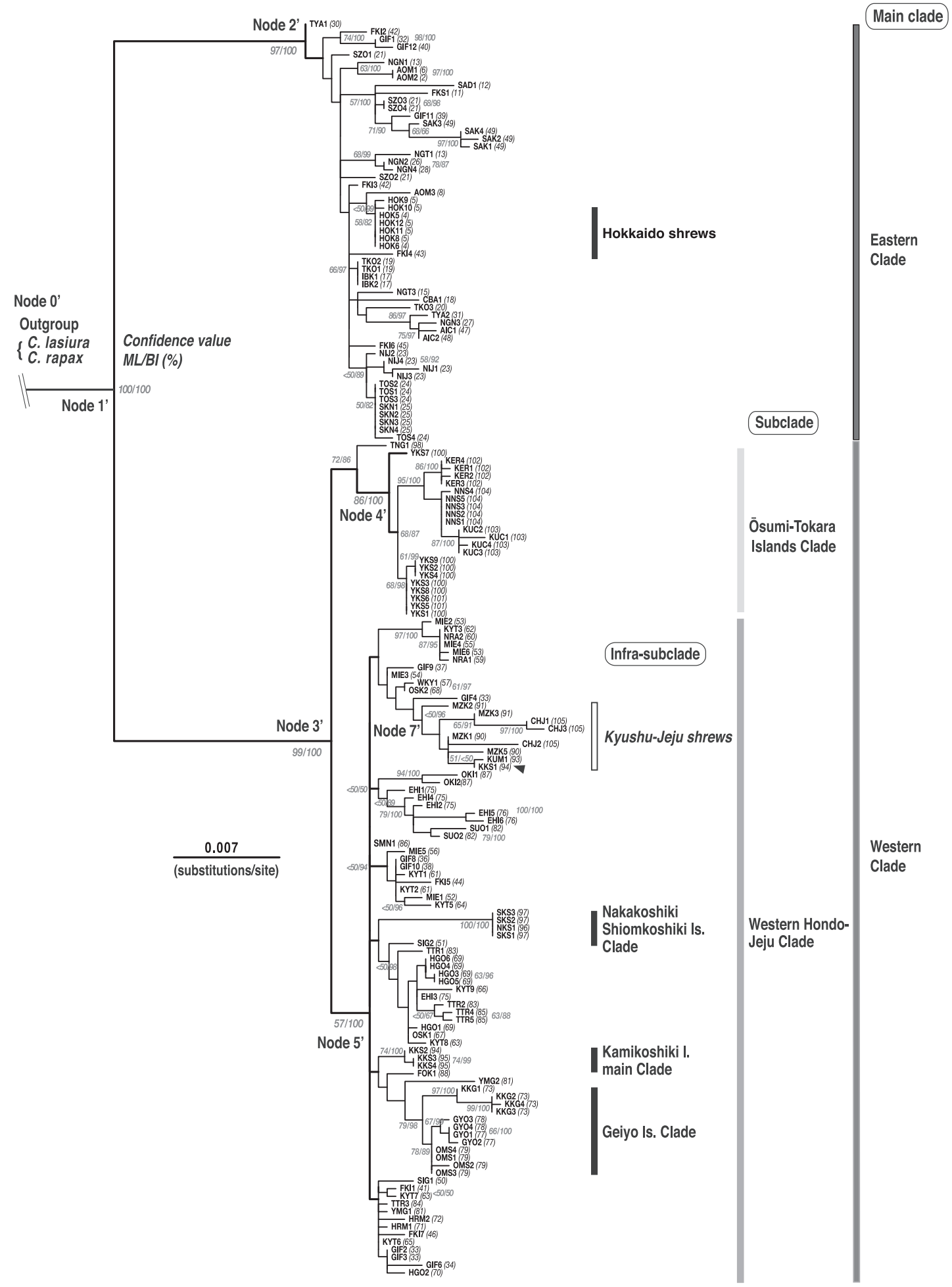

Fig. 2. Maximum likelihood (ML) tree based on the combined nucleotide sequence data set (1748 bp) of the mitochondrial cytochrome $b$ gene and the control region in Crocidura dsinezumi. Bootstrap values of maximum likelihood method and Bayesian posterior probabilities of Bayesian (BI) method are indicated near nodes as confidence in the nodes. When confidence value is less than $50 \%$, it is indicated as " $<50$ ". When both confidence values for ML and BI methods are less than 50\%, confidence values are omitted from the tree. See Supplementary Table S1 for codes of OTUs. Numbers in parentheses are location numbers, which correspond to those in Fig. 1 and Supplementary Table S1. Shrews from Kyushu-Jeju are indicated in italised letters with an open square bar to indicate that the bootstrap value of ML method is less than 50\%. A black triangle points to an individual from Kamikoshiki Island (KKS1) with an unusual phylogenetic position. Nodes 0'-5' and 7' correspond to those of Nodes 0-5 and 7 in Fig. 3. 


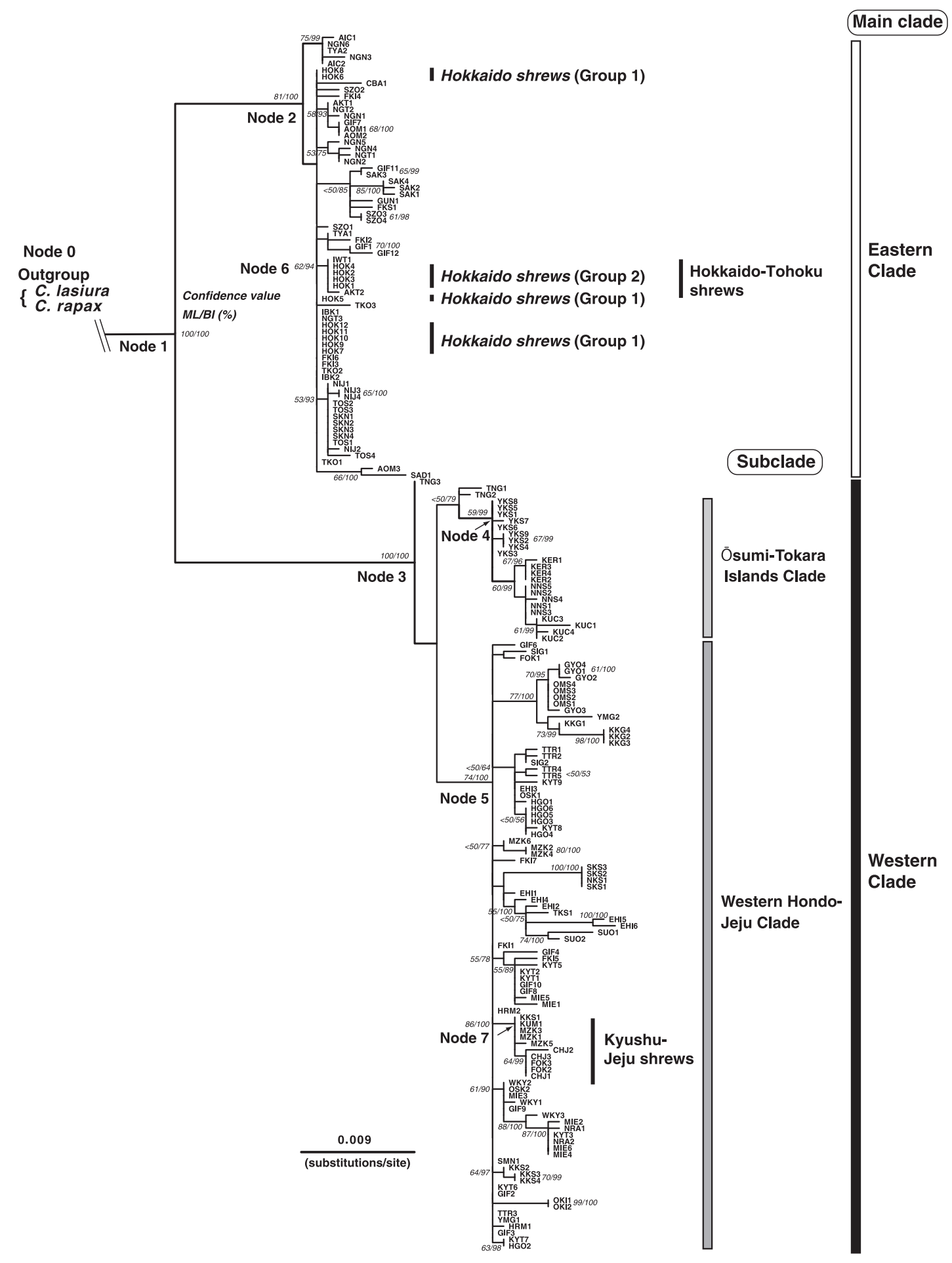

Fig. 3. Maximum likelihood (ML) tree based on mitochondrial cytochrome $b$ gene sequence (1140 bp) in Crocidura dsinezumi. Bootstrap values of maximum likelihood method and Bayesian posterior probabilities of Bayesian (BI) method are indicated near nodes as confidence in the nodes. When confidence value is less than $50 \%$, it is indicated by " $<50$ ". When both confidence values for ML and BI methods are less than $50 \%$, confidence values are omitted from the tree. See Supplementary Table S1 for codes of OTUs. 

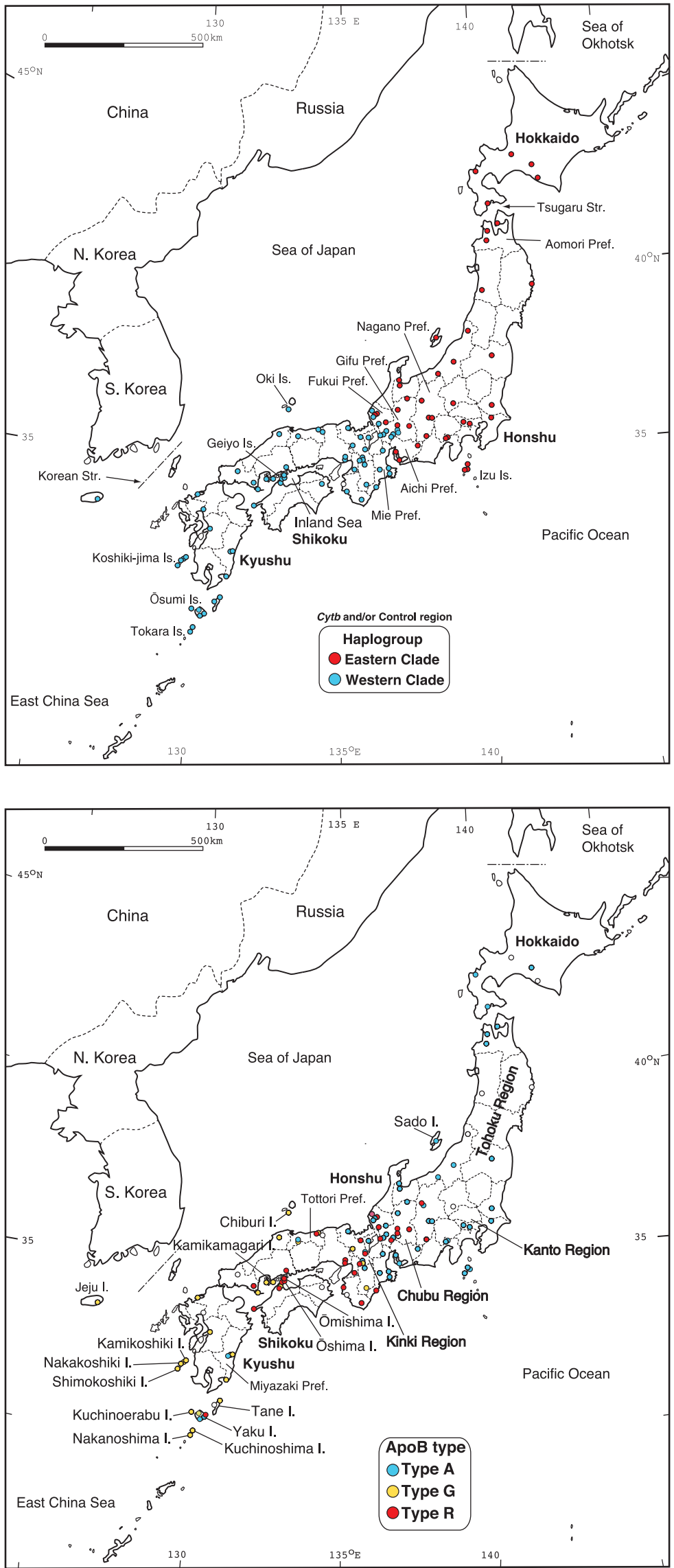

Fig. 4. Plot of the two major mitochondrial haplogroups (Eastern and Western Clades) of the cytochrome $b$ and/or the control region genes in Crocidura dsinezumi. Since location numbers are omitted in this figure, they are to be compared with Fig. 1. Haplogroup of a specific individual shrew should be referred to Supplementary Table S1. Open circles denote missing data.
Fig. 5. Plot of the three nuclear $A p o B$ gene types (Types $\mathrm{A}, \mathrm{G}$, and $\mathrm{R})$ of the nuclear apolipoprotein $\mathrm{B}(A p o B)$ gene in Crocidura dsinezumi. Compare with Fig. 1 for location numbers. Refer to Supplementary Table S1 for the haplogroup of specific individuals. If several types are found at a location, circles are overlaid with slight shift. Open circles denote missing data. 
A. Total

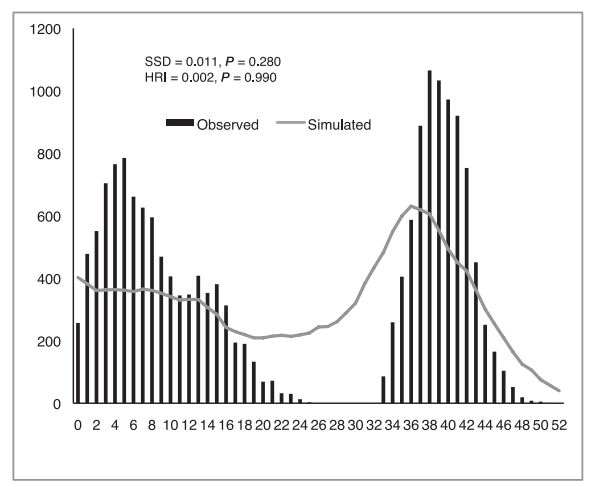

B. Eastern Clade (all)

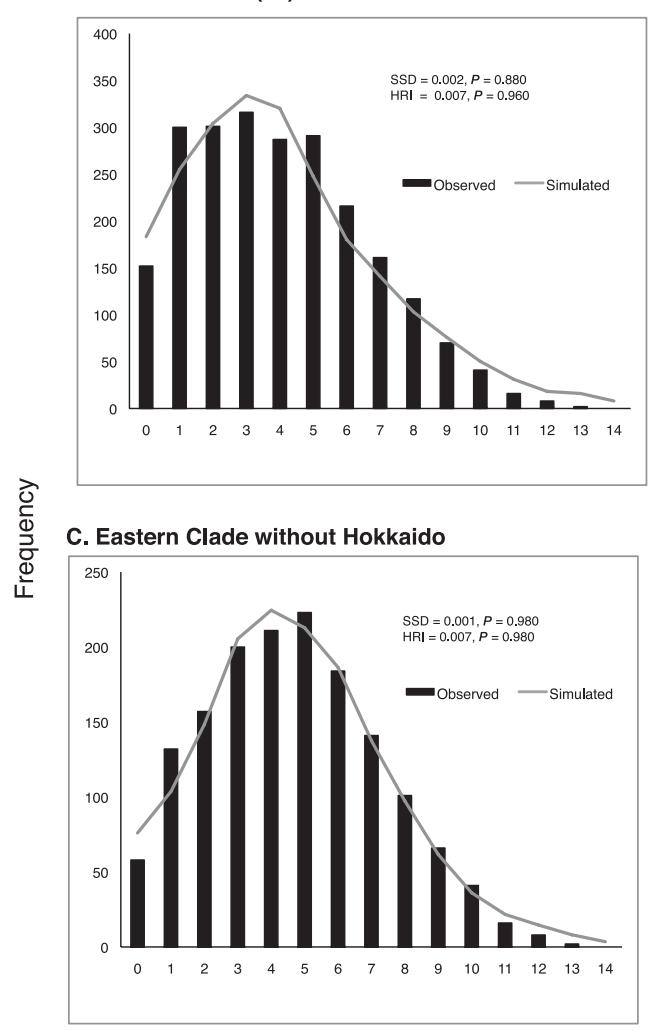

D. Hokkaido

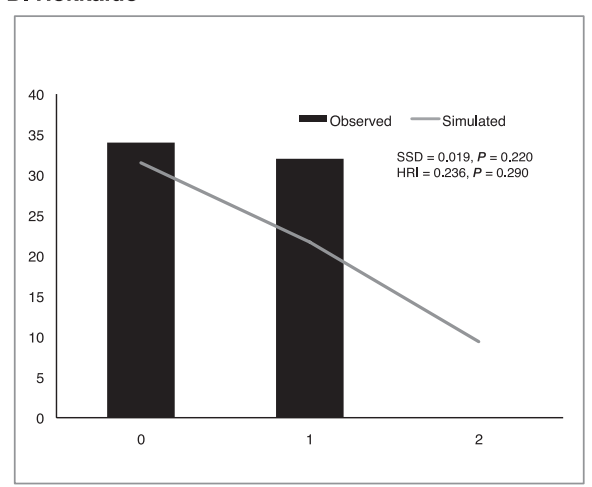

E. Western Clade (all)

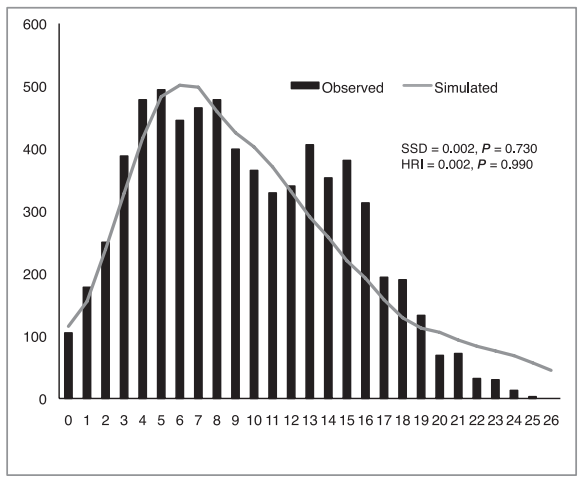

F. Western Clade without Ōsumi,Tokara, \& Jeju Is.

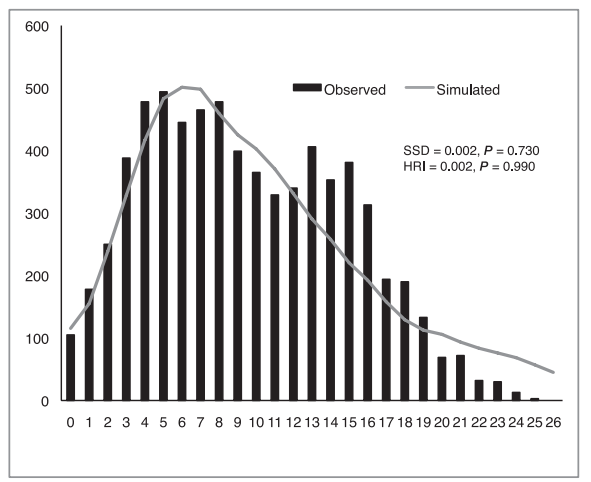

G. Ōsumi \& Tokara Is.

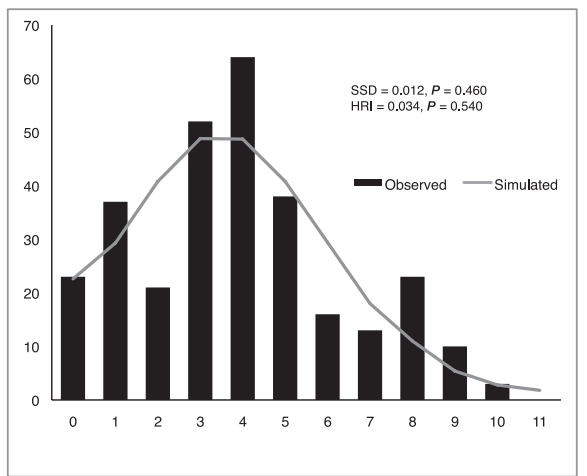

H. Jeju I.

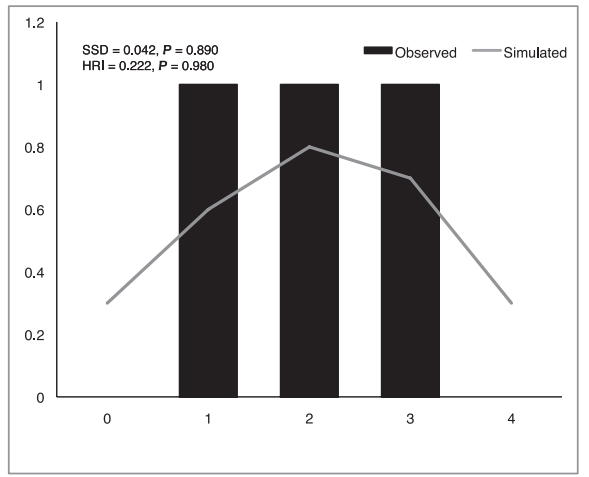

Pairwise differences

Fig. 6. Mismatch distribution of the mitochondrial cytochrome $b$ sequences in Crocidura dsinezumi. Vertical bars are observed frequency and a line is the expected frequency under the sudden expansion model. SSD, sum of squared deviation; HRI, Harpending's raggedness index; $P$, probability. 
Table 1. Neutrality tests using Tajima's $D$ and Fu's $F_{S}$ for seven populations of Crocidura dinezumi from Japan and Jeju (South Korea), based on the mitochondrial cytchrome $b$ nucleotide sequences. Note that a population is defined by geographic location, being independent from pylogenetic clade in Figs. 2 and 3, although Eastern and Western populations corresponds to Eastern and Western Clades, respectively

\begin{tabular}{lrrrrrrr}
\hline & Total & $\begin{array}{c}\text { Easten } \\
\text { population }\end{array}$ & $\begin{array}{c}\text { Eastern } \\
\text { Honshu } \\
\text { population }\end{array}$ & $\begin{array}{c}\text { Hokkaido } \\
\text { population }\end{array}$ & $\begin{array}{c}\text { Western } \\
\text { population }\end{array}$ & $\begin{array}{c}\text { Western } \\
\text { Hondo } \\
\text { population }\end{array}$ & $\begin{array}{c}\text { Osumi \& } \\
\text { Tokara islands }\end{array}$ \\
Island \\
Iajima's $D$ test
\end{tabular}

$* P<0.05$.

Eastern Honshu population $=($ Eastern population $)-($ Hokkaido population $)$.

Western Hondo population $=($ Western population $)-($ popolations from the Ōsumi \& Tokara Islands and Jeju Island $)$.

Table 2. Pairwise $\Phi_{S T}$ among five local populations from Japan and Jeju (South Korea) based on the mitochondrial cytchrome $b$ haplotypes of Crocidura dsinezumi

\begin{tabular}{lcccc}
\hline Population & 1 & 2 & 3 & 4 \\
\hline 1. Eastern Honshu & - & & & \\
2. Hokkaido & 0.03017 & - & & \\
3. Western Hondo & $0.85145^{*}$ & $0.8503^{*}$ & - & \\
4. Ōsumi \& Tokara Is. & $0.87848^{*}$ & $0.91969^{*}$ & $0.60674^{*}$ & - \\
5. Jeju & $0.89166^{*}$ & $0.98191^{*}$ & $0.23461^{*}$ & $0.76727^{*}$ \\
\hline
\end{tabular}

* Significant difference from zero $(P<0.05)$.

The Ōsumi Islands = Yaku, Tane, and Kuchinoerabu islands in the present paper.

deviation) (Fig. 6). This means that most groups examined did not deviate significantly from the sudden expansion model. In addition, total population showed a typical bimodal distribution (Fig. 6A).

Neutrality test showed that $p$-values for Tajima's $D$ for populations from Hokkaido, the Ōsumi-Tokara Islands, and Jeju Island were not significant $(P>0.05)$ (Table 1), although the probability of Fu's $F_{S}$ for the Ōsumi-Tokara Islands population was significant $(P<0.05)$. Tajima's $D s$ of the other populations were significantly negative $(P<0.05)$.

The genetic differentiation test by pairwise $\Phi_{S T}$ demonstrated that populations in eastern Honshu and Hokkaido were not genetically differentiated $(P>0.05)$ from each other, but that the other pairs were genetically differentiated (Table 2). This means that there is significant genetic differentiation between most populations except between eastern Honshu and Hokkaido.

\section{Divergence time}

Divergence times for the eight nodes on the phylogenetic tree based on the cytb sequences (Fig. 3) were estimated for six different evolutionary rate assumptions (Table 3). Under traditional assumptions of slow evolutionary rates $(2-4 \%)$, the mean separation period between Eastern and Western Clades (Node 1) was estimated to range from 0.513 to 1.047 million years ago (MYA) with a $95 \%$ confidence range of 0.387 to 1.305 MYA, whereas under assumptions of fast evolutionary rates $(8-17.1 \%)$ it ranged from 0.121 to 0.265 MYA with a $95 \%$ confidence range of 0.091-0.327 MYA (Table 3). The estimated divergence periods among Western Hondo-Jeju Clade, Ōsumi-Tokara Islands Clade, and shrews from Tane Island (Node 3) under the slow rates ranged from 0.196 to 0.412 MYA with a $95 \%$ confidence range of 0.138 0.523 MYA, whereas those under the rapid rates were from 0.046 to 0.106 MYA with a $95 \%$ confidence range of 0.033-0.130 MYA (Table 3). Additionally, mean estimated divergence periods within Hokkaido-Tohoku shrews (Node 6) and within Kyushu-Jeju shrews (Node 7) ranged from 0.012 to $0.043 \mathrm{MYA}$ and from 0.024 to 
Table 3. Node ages in millions of years with their $95 \%$ highest posterior density $(95 \%$ HPD) interval for six assumptions of clock rates (substitution/site/million year), based on mitochondrial cytochrome $b$ gene sequence

\begin{tabular}{|c|c|c|c|c|c|c|}
\hline \multirow[b]{2}{*}{ Node } & \multicolumn{3}{|c|}{ Slow clock rate } & \multicolumn{3}{|c|}{ Fast clock rate } \\
\hline & $2 \%$ & $3.1 \%$ & $4 \%$ & $8 \%$ & $12 \%$ & $17.1 \%$ \\
\hline Divegence period & $\begin{array}{c}\text { Mean } \\
{[95 \% \text { HPD }]}\end{array}$ & $\begin{array}{c}\text { Mean } \\
{[95 \% \text { HPD }]}\end{array}$ & $\begin{array}{c}\text { Mean } \\
{[95 \% \text { HPD }]}\end{array}$ & $\begin{array}{c}\text { Mean } \\
{[95 \% \mathrm{HPD}]}\end{array}$ & $\begin{array}{c}\text { Mean } \\
{[95 \% \mathrm{HPD}]}\end{array}$ & $\begin{array}{c}\text { Mean } \\
{[95 \% \mathrm{HPD}]}\end{array}$ \\
\hline $\begin{array}{l}\text { Node } 0 \\
\text { (C. dsinezumi/outgroup) }\end{array}$ & $\begin{array}{c}2.203 \\
{[1.803-2.589]}\end{array}$ & $\begin{array}{c}1.417 \\
{[1.166-1.672]}\end{array}$ & $\begin{array}{c}1.092 \\
{[0.902-1.294]}\end{array}$ & $\begin{array}{c}0.554 \\
{[0.450-0.646]}\end{array}$ & $\begin{array}{c}0.366 \\
{[0.301-0.430]}\end{array}$ & $\begin{array}{c}0.256 \\
{[0.212-0.303]}\end{array}$ \\
\hline $\begin{array}{l}\text { Node } 1 \\
\text { (Eastern/Western clades) }\end{array}$ & $\begin{array}{c}1.047 \\
{[0.776-1.305]}\end{array}$ & $\begin{array}{c}0.671 \\
{[0.500-0.837]}\end{array}$ & $\begin{array}{c}0.513 \\
{[0.387-0.649]}\end{array}$ & $\begin{array}{c}0.265 \\
{[0.196-0.327]}\end{array}$ & $\begin{array}{c}0.173 \\
{[0.130-0.218]}\end{array}$ & $\begin{array}{c}0.121 \\
{[0.091-0.152]}\end{array}$ \\
\hline $\begin{array}{l}\text { Node } 2 \\
\text { (within Eastern Clade) }\end{array}$ & $\begin{array}{c}0.250 \\
{[0.141-0.338]}\end{array}$ & $\begin{array}{c}0.159 \\
{[0.093-0.219]}\end{array}$ & $\begin{array}{c}0.116 \\
{[0.073-0.171]}\end{array}$ & $\begin{array}{c}0.065 \\
{[0.035-0.085]}\end{array}$ & $\begin{array}{c}0.041 \\
{[0.024-0.056]}\end{array}$ & $\begin{array}{c}0.027 \\
{[0.017-0.040]}\end{array}$ \\
\hline $\begin{array}{l}\text { Node } 3 \\
\text { (within Western Clade) }\end{array}$ & $\begin{array}{c}0.412 \\
{[0.275-0.523]}\end{array}$ & $\begin{array}{c}0.262 \\
{[0.180-0.333]}\end{array}$ & $\begin{array}{c}0.196 \\
{[0.138-0.260]}\end{array}$ & $\begin{array}{c}0.106 \\
{[0.069-0.130]}\end{array}$ & $\begin{array}{c}0.067 \\
{[0.046-0.087]}\end{array}$ & $\begin{array}{c}0.046 \\
{[0.033-0.061]}\end{array}$ \\
\hline $\begin{array}{l}\text { Node } 4 \\
\text { (within Ōsumi-Tokara Is. Cl.) }\end{array}$ & $\begin{array}{c}0.111 \\
{[0.046-0.146]}\end{array}$ & $\begin{array}{c}0.068 \\
{[0.030-0.094]}\end{array}$ & $\begin{array}{c}0.046 \\
{[0.023-0.073]}\end{array}$ & $\begin{array}{c}0.031 \\
{[0.011-0.037]}\end{array}$ & $\begin{array}{c}0.017 \\
{[0.008-0.024]}\end{array}$ & $\begin{array}{c}0.011 \\
{[0.005-0.017]}\end{array}$ \\
\hline $\begin{array}{l}\text { Node } 5 \\
\text { (within W. Hondo-Jeju Cl.) }\end{array}$ & $\begin{array}{c}0.275 \\
{[0.184-0.335]}\end{array}$ & $\begin{array}{c}0.175 \\
{[0.120-0.211]}\end{array}$ & $\begin{array}{c}0.128 \\
{[0.091-0.166]}\end{array}$ & $\begin{array}{c}0.072 \\
{[0.046-0.084]}\end{array}$ & $\begin{array}{c}0.044 \\
{[0.031-0.056]}\end{array}$ & $\begin{array}{c}0.03 \\
{[0.022-0.039]}\end{array}$ \\
\hline $\begin{array}{l}\text { Node } 6 \\
\text { (within Hokkaido-Tohoku shrews) }\end{array}$ & $\begin{array}{c}0.043 \\
{[0.005-0.052]}\end{array}$ & $\begin{array}{c}0.025 \\
{[0.003-0.034]}\end{array}$ & $\begin{array}{c}0.012 \\
{[0.002-0.026]}\end{array}$ & $\begin{array}{c}0.013 \\
{[0.001-0.014]}\end{array}$ & $\begin{array}{c}0.004 \\
{[0.000-0.005]}\end{array}$ & $\begin{array}{c}0.003 \\
{[0.000-0.006]}\end{array}$ \\
\hline $\begin{array}{l}\text { Node } 7 \\
\text { (within Kyushu-Jeju shrews) }\end{array}$ & $\begin{array}{c}0.062 \\
{[0.016-0.093]}\end{array}$ & $\begin{array}{c}0.041 \\
{[0.010-0.061]}\end{array}$ & $\begin{array}{c}0.024 \\
{[0.008-0.047]}\end{array}$ & $\begin{array}{c}0.020 \\
{[0.004-0.023]}\end{array}$ & $\begin{array}{c}0.010 \\
{[0.003-0.016]}\end{array}$ & $\begin{array}{c}0.006 \\
{[0.002-0.011]}\end{array}$ \\
\hline
\end{tabular}

Node names correspond to those in Fig. 3.

0.062 MYA, respectively, for slow evolutionary rates, and from 0.003 to 0.013 MYA (Node 6) and from 0.006 to 0.020 (Node 7) for fast evolutionary rates (Table 3).

\section{Discussion}

Phylogeography of the Japanese white-toothed shrew

There were two clear divisions of mitochondrial haplogroups (Fig. 2): Eastern and Western Clades. Eastern Clade occurs in the eastern part of Japan whereas Western Clade in the western part (Fig. 4). The demarcation line between the ranges of Eastern and Western Clades is unambiguously drawn in central Japan without overlap (Fig. 4).

For the nuclear $A p o B$ gene type, only a single mutation site was found in the $537 \mathrm{bp}$ region sequenced (Fig. 5). However, $A p o B$ gene offered new insight for the genetic structure of $C$. dsinezumi in addition to maternal information. Type A occurred mainly in eastern and central Japan and Types $G$ and R in central and western Japan and Jeju (South Korea). Thus, the individuals having adenine occur throughout Japan, whereas those having guanine tended to occur more frequently in the western and central parts of Japan and Jeju. Thus, it is suggested that gene flow might occur over the demarcation line between the ranges of the two haplogroups. However, more data of nuclear genes must be analysed for precise investigation of the gene flow between eastern and western Japan since there was only a single mutation in the present study.

Mismatch tests (Fig. 6) implied that most shrew populations did not deviate significantly from the sudden expansion model. This finding suggests that most populations might have experienced recent sudden population expansion. The total population of $C$. dsinezumi showed a typical bimodal distribution (Fig. 6A). This certainly is caused by unambiguous phylogenetic divergence of Eastern and Western populations (= Eastern and Western Clades in phylogenetic analysis; Figs. 2 and 3), because such bimodal distribution is often observed in a population with secondary contact of genetically well-diverged populations (Avise 2000).

According to the neutrality test (Table 1), Eastern population, Eastern Honshu population, Western population, and Western Hondo population deviated from the equilibrium of the neutral theory, suggesting recent expansion of population size because Tajima's $D$ and Fu's $F_{S}$ were significantly negative for most of these groups. Hokkaido population, Ōsumi-Tokara Islands population (only in 
Tajima's $D$ test), and Jeju population did not significantly deviate from equilibrium (Table 1), but this result might be an artifact of small sample sizes. Pairwise $\Phi_{S T}$ indicated that most local populations genetically differentiated from each other (Table 2), but there was no significant genetic differentiation between Eastern Honshu and Hokkaido populations. The Jeju population and the Western Hondo population including the Kyushu population were genetically differentiated (Table 2), although the phylogenetic tree showed Jeju shrews were genetically close to Kyushu shrews (Figs. 2 and 3). This also might be an artifact of small sample size of Jeju $(n=3)$. More samples from Jeju Island should be analyzed to determine the population genetic status of the Jeju shrews.

The average estimated separation period between Eastern and Western Clades (Node 1) was 0.513-1.047 MYA under the slow clock rates and 0.121-0.265 under the fast clock rates (Table 3, Fig. 3). During this period, Hondo (= Kyushu + Shikoku + Honshu) seems to have been connected to the Asian Continent via the Korean Peninsula (e.g., Ohshima 1990, 1991; Kimura 2002) although the lowest 95\% limit (0.091 MYA; Table 3) estimated by the $17.1 \%$ fast clock rate is younger than the geological division between Hondo and the Asian Continent. Thus, separation between the two main haplogroups might have occurred before Hondo and the Asian Continent were geologically separated. How and where the two main haplogroups were established also needs to be investigated in future. Furthermore, how clear demarcation of the two haplogroups is maintained in Honshu is an attractive question since there has been no clear geographic barrier at present between the eastern and western parts of Honshu since the Pliocene (Minato 1978; Noda and Goto 2003).

Crocidurine shrews (Crocidurinae) often colonize non-native regions through unintentional human introduction (Vogel et al. 1986; Vogel and Sofianidou 1996; Esselstyn and Oliveros 2010; Motokawa 2015b; Aulagnier et al. 2017). For C. dsinezumi, human introduction into Hokkaido and Jeju Island has been suggested by Han et al. (2002), Ohdachi et al. (2004), and Ohdachi (2008). However, the original regions of these introduced populations were not revealed in those previous investigations.

According to the analyses based on the data set of $c y t b$ only, the shrews in Hokkaido were divided into two groups (Fig. 3), suggesting multiple origins of Hokkaido shrews. We cannot deny natural distribution in Hokkaido for some of the Hokkaido shrews (Group 1), judging from their phylogenetic positions (Fig. 3). The other shrews in
Hokkaido (Group 2) were clustered in a clade with two individuals from the Tohoku Region (IWT1 and AKT2, Fig. 3). The shrews in Jeju were clustered in a clade with those from the Kyushu mainland and Kamikoshiki Island in both data sets (Figs. 2 and 3). The Tsugaru and Korean Straits are estimated to have formed approximately 100 150 KYA (Ohshima 1990, 1991). However, estimated divergence times for the Hokkaido-Tohoku shrews (Node 6, Fig. 3) and the Kyushu-Jeju shrews (Node 7) are much younger than geological separations of Hokkaido from Honshu and of Jeju from Kyushu (Table 3). This result suggests that some Hokkaido shrews (Group 2) were introduced recently from eastern Honshu (possibly the Tohoku Region) and Jeju shrews from Kyushu, although we cannot discard the scenario that the two shrews in Tohoku were introduced from Hokkaido. In either case, it is inferred that $C$. dsinezumi was recently moved between Hokkaido and the Tohoku Region.

Additionally, one individual from Kamikoshiki Island (KKS1) was phylogenetically closed to those on the Kyushu mainland, whereas the other individuals on the island were clustered in a clade (Kamikoshiki Island Main Clade; Figs. 2 and 3). This finding also suggests that recent introduction might have occurred on Kamikoshiki Island.

\section{Relationship between phylogeny and morphotype}

Motokawa (2003) demonstrated, based on cranial measures, that the body size of $C$. dsinezumi had a negative correlation with latitude, but the shrews in Hokkaido and Kuchinoerabu Island were larger than expected (see Fig. 5 for locations). However, it was shown that the Hokkaido population was phylogenetically close to the shrews in eastern Honshu (Fig. 2). The shrews on Kuchinoerabu Island are genetically similar to those from Kerama and Nakanoshima Islands (Figs. 2 and 3). Therefore, the morphological change in Hokkaido and Kuchinoearabu Island could be the result of morphological plasticity without genetic background. Thus, a subspecific rank for the population on Kuchinoerabu Island, which was suggested by Motokawa (2003), should be carefully considered.

Takada et al. (2013) revealed that, based on mandibular morphology, shrews of the Izu Islands were morphologically similar to those on the Kyushu mainland and thus suspected that the populations in Kyushu and the Izu Islands might be genetically close to each other. The present study, however, clearly shows that these two populations have completely separate phylogenetic positions 
(Figs. 2 and 3). Hence, the morphological similarity noted by Takada et al. (2013) is a result of convergence or just by chance.

\section{Comparison with phylogeographic studies on some} other small mammals

The large Japanese field mouse (A. speciosus) possesses two different karyotypes in eastern and western Japan respectively, and shows a hybrid form between them in central Honshu (Tsuchiya 1974). The hybrid form exists near the Toyama-Hamamatsu line (Iwasa 2015), which is close to the border line between the two major haplogroups of C. dsinezumi (Fig. 4) although the line for C. dsinezumi extends farther westward than the ToyamaHamamatsu line. However, there is no such east-west genetic divergence in the nuclear and mitochondrial DNA in A. speciosus (Suzuki et al. 2004; Tomozawa and Suzuki 2008). Similarly, the Japanese shrew-mole (Urotrichus talpoides) also has two different karyotypes in eastern and western Japan respectively, the demarcation line being located in central Honshu (Tsuchiya 1988). The demarcation line of $U$. talpoides extends from Fukui Prefecture to Mie Pref. via Shiga Pref. This line is similar to that between the two major haplogroups of C. dsinezumi (Fig. 4) although the southern part of the line for $C$. dsinezumi is posited a little more eastward than that for $U$. talpoides. The border between the two haplogroups of cytb gene in the Japanese hare (Lepus brachyurus) is found in the west of the Kinki Region (Nunome et al. 2010) and the border between the two haplogroups of the Sry gene on Y chromosome is located in eastern Honshu (Nunome et al. 2014). Both demarcation lines of L. brachyurus are quite different from that of the two main haplogroups in $C$. dsinezumi and were estimated to have diverged before the Middle Pleistocene.

Thus, the demarcation lines between the ranges of genetic types in several terrestrial small and medium mammal species are similar to that of the Eastern and Western Clades of the mitochondrial genes in $C$. dsinezumi. The border is located in central Honshu, and shows only slight deviation among animal species, except for L. brachyurus. It appears that, based on palaeomaps of the Japanese Islands, there has been no prominent geologic barrier to the movement of small animals in central Honshu since the Pliocene (Minato 1978; Noda and Goto 2003). However, altitude seems to have formed an incomplete barrier in the dispersal of $A$. speciosus in central Honshu. The environment above $1600 \mathrm{~m}$ a.s.l. is unsuitable for A. speciosus and this unsuitable area expanded during the last glacial maximum (Shintaku and Motokawa 2016). Therefore, some climatic conditions such as altitude and temperature may have affected the genetic distribution patterns of the other small mammals. The correlation between climatic condition and distribution of genetic types is to be analyzed in the next stage to develop the result of the present study.

\section{Supplementary data}

Supplementary data are available at Mammal Study online. Supplementary Table S1. List of sample codes, capture localities, accession numbers, and data sources for the shrews used in the present study

Supplementary Data S1. Aligned nucleotide sequences data set (Nexus formatted) for the mitochondrial cytochrome $b$ gene and control region in Crocidura dsinezumi and two related species.

Acknowledgments: Some of the samples of shrews examined were provided by Fukui City Museum of Natural History (Yukako Naitoh), Osaka Museum of Natural History (Makiko Nishizawa and Takeshi Wada), Taga Town Museum (Yuji Abe and Shigefumi Kanao), Tottori Prefectural Museum (Kei Ichisawa), Sang-Hoon Han, Keiichi Kajiura, Zenkichi Shimizu, Yukako Naitoh, Hisashi Abe, Hiroaki Kariwa, Akio Shinohara, Jun J. Sato, Koichi Takeno, Kaito Okabe, Yoshihiro Matsuura, Kazuhiro Nishii, and Masashi Harada. Tomoyuki Namba and Yukako Naitoh helped with field work. Hitoshi Suzuki, Wataru Ohnishi, Tomohiro Nakayama, and Kazuhiro Koyasu assisted in collecting preserved samples. Masaru Kato collected detailed information for several samples. Also, Akira Sano, Makoto Asano, Masatsugu Suzuki, Shirow Tatsuzawa provided us with information about museums and private collections in which $C$. dsinezumi is preserved. Masatoshi Yasuda and Hidetoshi Ota provided us with information on the geological and biogeographical history of the southern islands of Japan. Karli Lawson-Shimizu proofed the English for an earlier version of the manuscript. Leslie Carraway also reviewed an earlier version of the manuscript. We express our deep gratitude to them. Author contributions were as follows: S.D.O. led the study and conducted field and laboratory work; K.Y. performed the phylogenetic analyses; Y.T., M.M. and M.A.I. collected shrew samples; S.A. conducted field and laboratory work. G.K. performed the estimation of divergence time between the shrew clades and population genetic 
analyses, and the seven authors above profoundly contributed to the present study though discussion; J.M., Y.U., E.S., T.T., and HSO conducted material collection.

\section{References}

Anderson, S., Bankier, A. T., Barrell, B. G., de Bruijn, M. H., Coulson, A. R., Drouin, J., Eperon, I. C., Nierlich, D. P., Roe, B. A., Sanger, F. et al. 1981. Sequence and organization of the human mitochondrial genome. Nature 290: 457-465.

Arai, S., Gu, S. H., Baek, L. J., Tabara, K., Bennett, S. N., Oh, H. S., Takada, N., Kang, H. J., Tanaka-Taya, K., Morikawa, S. et al. 2012. Divergent ancestral lineages of newfound hantaviruses harbored by phylogenetically related crocidurine shrew species in Korea. Virology: 424: 99-105.

Aulagnier, S., Hutterer, R., Jenkins, P., Bukhnikashvili, A., Kryštufek, B. and Kock, D. 2017. Suncus etruscus. The IUCN Red List of Threatened Species. 2017: e.T90389138A22288134. DOI: 10.2305/ IUCN.UK.2017-2.RLTS.T90389138A22288134.en.

Avise, J. C. 2000. Phylogeography. The History and Formation of Species. Harvard University Press, Cambridge, 464 pp.

Bouckaert, R., Heled, J., Kuhnert, D., Vaughan, T., Wu, C. H., Xie, D., Suchard, M. A., Rambaut, A. and Drummond, A. J. 2014. BEAST 2: a software platform for Bayesian evolutionary analysis. PLoS Computational Biolology 10: e1003537. DOI: 10.1371/journal. pcbi.1003537.

Brown, W. M. 1980. Polymorphism in mitochondrial DNA of humans as revealed by restriction endonuclease analysis. Proceedings of the National Academy of Sciences, USA 77: 3605-3609.

Brown, W. M., George, M., Jr. and Wilson, A. C. 1979. Rapid evolution of animal mitochondrial DNA. Proceedings of the National Academy of Sciences 75: 1967-1971.

Dubey, S., Salamin, N., Ohdachi, S. D., Barrière, P. and Vogel, P. 2007. Molecular phylogenetics of Soricidae (Mammalia, Soricidae) reveals timing of transcontinental colonisations. Molecular Phylogenetics and Evolution 44: 126-137.

Esselstyn, J. A. and Oliveros, C. H. 2010. Colonization of the Philippines from Taiwan: a multi-locus test of the biogeographic and phylogenetic relationships of isolated populations of shrews. Journal of Biogeography 37: 1504-1514.

Excoffier, L. and Lischer, H. E. L. 2010. Arlequin suite ver 3.5: a new series of programs to perform population genecisc analyes under Linux and Windows. Molecular Ecology Resources 10: 564-567.

Guindon, S., Dufayard, J. F., Lefort, V., Anisimova, M., Hordijk, W. and Gascuel, O. 2010. New algorithms and methods to estimate maximum-likelihood phylogenies: Assessing the performance of PhyML 3.0. Systematic Biology 59: 307-321.

Han, S. H., Iwasa, M. A., Ohdachi, S. D., Oh, H. S., Suzuki, H., Tsuchiya, K. and Abe, H. 2002. Molecular phylogeny of Crocidura shrews in northeastern Asia: a special reference to specimens on Cheju Island, South Korea. Acta Theriologica 47: 369-379.

Hattori, S., Noboru, Y. and Yamanouchi, K. 1986. Domestication of the Watase's shrew, Crocidura horsfieldi watasei, for a laboratory animal. The Japanese Journal of Experimental Medicine 56: 75-79.

Ho, S. Y., Phillips, M. J., Cooper, A. and Drummond, A. J. 2005. Time dependency of molecular rate estimates and systematic overestimation of recent divergence times. Molecular Biology and Evolution 22: 1561-1568.

Iwasa, M. A. 2015. Apodemus speciosus (Temminck, 1844). In (Ohdachi, S. D., Ishibashi, Y., Iwasa, M. A., Fukui, D. and Saitoh,
T., eds). The Wild Mammals of Japan, Second edition, pp. 175177. Shoukadoh, Kyoto.

Katoh, K., Kuma, K. I., Toh, H. and Miyata, T. 2005. MAFFT version 5: improvement in accuracy of multiple sequence alignment Nucleic Acids Research 33: 511-518.

Kimura, M. 2002. The fomation and the paleogeology of the Ryuku Arc. In (Kimura, M., ed.) The Formation of the Ryukyu Arch and Migration of Biota to the Arc, pp. 19-54. The Okinawa Times Inc., Naha (in Japanese).

Lin, L. K. and Motokawa, M. 2014. Mammals of Taiwan. Center for Tropical Ecology and Biodiversity, Tunghai University, Taichung, Taiwan, $89 \mathrm{pp}$

Minato, M. 1978. The History of the Japan Islands. Palaeo-Maps. Tukiji Shokan, Tokyo, 120 pp. (in Japanese).

Miyata, T., Hayashida, H., Kikuno, R., Hasegawa, M., Kobayashi, M. and Koike, K. 1982. Molecular clock of silent substitution: at least six-fold preponderance of silent changes in mitochondrial genes over those in nuclear genes. Journal of Molecular Evolution 19: $28-35$.

Motokawa, M. 2003. Geographic variation in the Japanese whitetoothed shrew Crocidura dsinezumi. Acta Theriologica 48: 145156.

Motokawa, M. 2015a. Crocidura dsinezumi (Temminck, 1842). In (Ohdachi, S. D., Ishibashi, Y., Iwasa, M. A., Fukui, D. and Saitoh, T., eds.) The Wild Mammals of Japan, Second edition, pp. 23-24. Shoukadoh, Kyoto.

Motokawa, M. 2015b. Suncus murinus (Linnaeus, 1766). In (Ohdachi, S. D., Ishibashi, Y., Iwasa, M. A., Fukui, D. and Saitoh, T., eds.) The Wild Mammals of Japan, Second edition, pp. 26-27. Shoukadoh, Kyoto.

Motokawa, M., Suzuki, H., Harada, M., Lin, L. K., Koyasu, K. and Oda, S. I. 2000. Phylogenetic relationships among East Asian species of Crocidura (Mammalia, Insectivora) inferred from mitochondrial cytochrome $b$ gene sequences. Zoological Science 17: 497-504.

Nabholz, B., Glemin, S. and Galtier, N. 2008. Strong variations of mitochondrial mutation rate across mammals - the longevity hypothesis. Molecular Biology and Evolution 25: 120-130.

Noda, Y. and Goto, M. 2003. Paleogeographic maps of the Japanese Islands and their application to exhibition of the Fukui Prefectural Dinosaur Museum. Memoirs of Fukui Prefectural Dinosaurs Museum 3: 47-63 (in Japanese with English abstract).

Nunome, M., Kinoshita, G., Tomozawa, M., Torii, H., Matsuki, R., Yamada, F., Matsuda, Y. and Suzuki, H. 2014. Lack of association between winter coat colour and genetic population structure in the Japanese hare, Lepus brachyurus (Lagomorpha: Leporidae). Biological Journal of Linnean Society 111: 761-776.

Nunome, M., Torii, H., Matsuki, R., Kinoshita, G. and Suzuki, H. 2010. The influence of pleistocene refugia on the evolutionary history of the Japanese hare, Lepus brachyurus. Zoological Science 27: $746-754$.

Nylander, J. A. A. 2004. MrModeltest v2. Evolutionary Biology Centre, Uppsala University, Uppsala. Available at http://www. abc.se/ nylander/mrmodeltest $2 /$ mrmodeltest $2 . h t m l$ (Accessed 1 October 2015)

Ohdachi, S. 1995. Diets and abundances of three sympatric shrew species in northern Hokkaido. Journal of the Mammalogical Society of Japan 20: 69-83.

Ohdachi, S. 2008. Phylogeography and genetic structure of shrews. In (Motokawa, M, ed.) Mammalogy in Japan. Vol. 1. Small Mammals, pp. 84-117. Tokyo University Press, Tokyo (in Japanese).

Ohdachi, S. D., Hasegawa, M., Iwasa, M. A., Abe, H., Vogel, P., Oshida, T. and Lin, L. K. 2006. Molecular phylogenetics of soricid 
shrews (Mammalia) based on mitochondrial cytochrome $b$ gene sequences: with special reference to the Soricinae. Journal of Zoology, London 270: 177-191.

Ohdachi, S. D., Iwasa, M. A., Nesterenko, V. A., Abe, H., Masuda, R. and Haberl, W. 2004. Molecular phylogenetics of Crocidura shrews (Insectivora) in East and Central Asia. Journal of Mammalogy 85: 396-403.

Ohdachi, S. D., Yoshizawa, K., Hanski, I., Kawai, K., Dokuchaev, N. E., Sheftel, B. I., Abramov, A. V., Moroldoev, I. and Kawahara, A. 2012. Intraspecific phylogeny and nucleotide diversity of the least shrews, the Sorex minutissimus-S. yukonicus complex, based on nucleotide sequences of the mitochondrial cytochrome $b$ gene and the control region. Mammal Study 37: 281-297.

Ohshima, K. 1990. The history of straits around the Japanese Islands in the late-Quaternary. The Quaternary Research 29: 193-208 (in Japanese with English abstract).

Ohshima, K. 1991. The late-Quaternary sea-level change of the Japanese Islands. Journal of Geography 100: 967-975 (in Japanese).

Posada, D. and Crandall, K. A. 1998. Modeltest: testing the model of DNA substitution. Bioinformatics 14: 817-818.

Rambaut, A. 2012. FigTree. V 1.4.0. Available at http://tree.bio.ed.ac. uk/software/figtree/ (Accessed 1 October 2015).

Rambaut, A. and Drummond, A. J. 2007. Tracer v 1.6. Available at http://tree.bio.ed.ac.uk/software/tracer (Accessed 1 October 2015).

Ronquist, F., Teslenko, M., Van Der Mark, P., Ayres, D. L., Darling, A., Höhna, S., Larget, B., Liu, L., Suchard, M. A. and Huelsenbeck, J. P. 2012. MrBayes 3.2: efficient Bayesian phylogenetic inference and model choice across a large model space. Systematic Biology 61: 539-542.

Schneider, S. and Excoffier, L. 1999. Estimation of past demographic parameters from the distribution of pairwise differences when the mutation rates vary among sites: application to human mitochondrial DNA. Genetics 152: 1079-1089.

Shintaku, Y. and Motokawa, M. 2016. Geographic variation in skull morphology of the large Japanese field mice, Apodemus speciosus (Rodentia: Muridae) revealed by geometric morphometric analysis. Zoological Science 33: 132-145.

Simmons, M. P. 2004. Independence of alignment and tree search. Molecular Phylogenetics and Evolution 31: 874-879.

Suzuki, Y., Tomozawa, M., Koizumi, Y., Tsuchiya, K. and Suzuki, H.
2015. Estimating the molecular evolutionary rates of mitochondrial genes referring to Quaternary ice age events with inferred population expansions and dispersals in Japanese Apodemus. BMC Evolutionary Biology 15: 187. DOI: 10.1186/s12862-0150463-5.

Suzuki, H., Yasuda, S. P., Sakaizumi, M., Wakana, S., Motokawa, M. and Tsuchiya, K. 2004. Differential geographic patterns of mitochondrial DNA variation in two sympatric species of Japanese wood mice, Apodemus speciosus and A. argenteus. Genes \& Genetic Systems 79: 165-176.

Takada, Y., Uematsu, Y., Sakai, E. and Tateishi, T. 2013. Morphological variation among island populations of Japanese white-toothed shrews (Crocidura dsinezumi) in central and western Japan. Honyurui Kagaku (Mammalian Science) 53: 67-77 (In Japanese with English summary).

Tomida, Y. and Sakura, H. 1991. Catalogue of Small Mammal (Insectivora, Lagomorpha, Chiroptera, \& Rodentia). Fossil Specimens. The National Science Museum (Tokyo), Tokyo, 205 pp.

Tomozawa, M. and Suzuki, H. 2008. A trend of central versus peripheral structuring in mitochondrial and nuclear gene sequences of the Japanese wood mouse, Apodemus speciosus. Zoological Science 25: 273-285.

Tsuchiya, K. 1974. Cytological and biochemical studies of Apodemus speciosus group in Japan. The Journal of the Mammalogical Society of Japan 6: 67-87 (in Japanese with English summary).

Tsuchiya, K. 1988. Cytotaxonomic studies of the family Talpidae from Japan. Honyurui Kagaku (Mammalian Science) 28: 49-61 (in Japanese).

Vogel, P., Maddalena, T. and Catzeflis, F. 1986. A contribution to taxonomy and ecology of shrews (Crocidura zimmermanni and C. suaveolens) from Crete and Turkey. Acta Theriologica 31: 537-545.

Vogel, P. and Sofianidou, T. S. 1996. The shrews of the genus Crocidura on Lebos, an eastern Mediterranean Island. Zoologische Beiträge 46: 339-347.

Received 23 August 2017. Accepted 8 August 2018. Published online 19 October 2018. Editor was Jun J. Sato. 